\title{
Drivers of differential views of health equity in the U.S.: is the U.S. ready to make progress? Results from the 2018 National Survey of Health Attitudes
}

Vivian L. Towe ${ }^{1}$, Linnea Warren May ${ }^{2 *}$ (D) Wenjing Huang ${ }^{2}$, Laurie T. Martin², Katherine Carman², Carolyn E. Miller ${ }^{3}$ and Anita Chandra ${ }^{2}$

\begin{abstract}
Objectives: The public health sector has long recognized the role of the social determinants of health in health disparities and the importance of achieving health equity. We now appear to be at an inflection point, as we hear increasing demands to dismantle structures that have perpetuated inequalities. Assessing prevailing mindsets about what causes health inequalities and the value of health equity is critical to addressing larger issues of inequity, including racial inequity and other dimensions. Using data from a nationally representative sample of adults in the United States, we examined the factors that Americans think drive health outcomes and their beliefs about the importance of health equity.
\end{abstract}

Methods: Using data from the 2018 National Survey of Health Attitudes, we conducted factor analyses of 21 survey items and identified three factors from items relating to health drivers - traditional health influencers (THI), social determinants of health $(\mathrm{SDoH})$, and sense of community health $(\mathrm{SOC})$. Health equity beliefs were measured with three questions about opportunities to be healthy. Latent class analysis identified four groups with similar patterns of response. Factor mixture modeling combined factor structure and latent class analysis into one model. We conducted three logistic regressions using latent classes and demographics as predictors and the three equity beliefs as dependent variables.

Results: Nearly $90 \%$ of respondents comprised one class that was characterized by high endorsement (i.e., rating the driver as having strong effect on health) of THI, but lower endorsement of SDoH and SoC. Logistic regressions showed that respondents endorsing (i.e., rated it as a top priority) all three health equity beliefs tended to be female, older, Black or Hispanic, more educated, and have lower incomes. The class of respondents that endorsed $\mathrm{SDoH}$ the most was more likely to endorse all three equity beliefs.

(Continued on next page)

\footnotetext{
* Correspondence: linneam@rand.org

${ }^{2}$ RAND Corporation, 4570 Fifth Avenue, Suite 600, Pittsburgh, PA 15213, USA

Full list of author information is available at the end of the article
}

(c) The Author(s). 2021 Open Access This article is licensed under a Creative Commons Attribution 4.0 International License, which permits use, sharing, adaptation, distribution and reproduction in any medium or format, as long as you give appropriate credit to the original author(s) and the source, provide a link to the Creative Commons licence, and indicate if changes were made. The images or other third party material in this article are included in the article's Creative Commons licence, unless indicated otherwise in a credit line to the material. If material is not included in the article's Creative Commons licence and your intended use is not permitted by statutory regulation or exceeds the permitted use, you will need to obtain permission directly from the copyright holder. To view a copy of this licence, visit http://creativecommons.org/licenses/by/4.0/. The Creative Commons Public Domain Dedication waiver (http://creativecommons.org/publicdomain/zero/1.0/) applies to the data made available in this article, unless otherwise stated in a credit line to the data. 
(Continued from previous page)

Conclusions: Results suggested that people historically impacted by inequity, e.g., people of color and people with low incomes, had the most comprehensive understanding of the drivers of health and the value of equity. However, dominant beliefs about SDoH and health equity are still generally not aligned with scientific consensus and the prevailing narrative in the public health community.

Keywords: Health equity, Population health, Health disparities, Social determinants of health

\section{Background}

In 2008 the WHO Commission on the Social Determinants of Health called reducing health inequities an "ethical imperative" [1]. In America today, racial inequity is now a significant part of the discourse, spurred by the unequal burden of the COVID-19 pandemic and nationwide demonstrations calling for police and systems reform. Incomes have been rising, but most gains have been concentrated among the top earners, resulting in increasing income inequality [2]. Inequity in the United States is driven by a lack of just and fair access to opportunity, rooted in historical and social context, including a history of racism [3]. There are emerging efforts to enact policies and even restructure government to dismantle systemic barriers that have impeded the realization of equity in the U.S. As we continue to hear demands to break down these entrenched structures, assessing prevailing mindsets about health equity becomes critical to addressing larger inequity issues.

The U.S. is currently undergoing a set of experiences that further underscore a persistent lack of equity across numerous sectors-sectors that create major disparities in health by race/ethnicity, income, education, and other inequities. Prior to the events of 2020, equity concerns had been a focus of some health departments, mayor's offices, philanthropies, and an explicit goal of the U.S. public health community for over a decade [4]. This focus emerged from persistently poor health outcomes disproportionately affecting low-income people and people of color [5, 6], and entrenched negative influences on health in some communities that can compound over generations. Called the social determinants of health, factors such as income, education, employment, and housing (including where people live) contribute to $50 \%$ of the variability in the distribution of length and quality of life [7] and are largely responsible for the disparities in health we observe. The data from sectors that influence health are hard to ignore: Black Americans are 5.1 times more likely than White Americans to be incarcerated [8]. In 2019, Black Americans earned 61 cents for every dollar White Americans earned (and Hispanic Americans earned 74 cents), disparities which have remained largely unchanged over the last 20 years [9]. Within racial/ethnic groups, lower income people are more likely than higher income people to lack access to care and have poorer self-reported general health [5].
Despite growing scientific consensus about the social determinants' role in achieving health equity [1, 10-14], evidence to date shows that most Americans are unaware of these health gaps, do not understand what causes them, and do not necessarily find them to be "unfair" (a cornerstone of perceptions of inequity) and thus not worthy of action. With regards to health disparities, a survey conducted in 2008-2009 based on a national sample showed that most respondents (73\%) were aware of health differences between the poor and middle class people, but less than half (46\%) reported awareness of health differences between White and Black Americans [15]. Furthermore, American mindsets place the responsibility for these outcomes on individual behaviors such as smoking, diet, and exercise, as well as access to clinical care as the primary drivers, and less so the social determinants of health [16-19]. For example, while $86 \%$ of respondents of the same survey considered individual behaviors to drive health, only $31 \%$ considered where a person lives to be a factor [18], a belief more commonly held by White respondents than non-White and Hispanic respondents. (A comparable survey of Wisconsin residents found similar results [19].) Finally, political and community action are often motivated by perceptions of unfairness, so an understanding of the extent to which people believe health inequity is unfair is critical to inspiring actions that improve health [20]. Previous research has examined the degree to which Americans believe health disparities and differences in access to health promoting resources are unfair, perceptions about the source of those disparities (race, income, education, etc.), and the level of support for actions to address disparities. Across studies, survey respondents perceived systemic barriers to accessing health care as being somewhat unfair yet experiencing disparate life expectancies by race/ethnicity was perceived as less unfair. In general, the belief that individual choices mainly drive health outcomes has inhibited perceptions that disparities in health outcomes are unfair and thus warranting policy action [19, 21, 22].

This evidence suggests examining whether demands for equity reported in the media truly translate into broad public support for policies to improve health equity. The lack of consensus around equity documented in the literature also calls into question the role "echo chambers" 
(social environments where individuals only encounter beliefs similar to their own) which can fuel polarization and perceptions of "otherness," and have perpetuated the conditions that cause inequity and inhibited widespread public support for systems change [16-19, 22, 23]. Given that most studies on beliefs about health disparities and equity were completed 10 years ago and much has changed regarding shared dialogue, a more recent assessment of health equity views is needed [16-19].

Previous work based on a 2015-2016 national survey provided evidence of a lack of understanding about the relationship between social determinants and health equity [16]. Misalignment between beliefs in health equity as a value and the contribution of the social determinants to health outcomes highlights a potential misunderstanding about the fundamental origins of inequities in upstream drivers of health. Since the latest research on similar questions was conducted, movements like Black Lives Matter have elevated the dialogue about race inequity. This study allows us to examine whether beliefs changed as awareness increased. This research contributes further by examining perceptions of fairness around the distribution of the social determinants or health equity, which is critical for motivating community action. Past research has not examined dominant health narratives by examining the relationship between understanding of health drivers and beliefs about health equity by demographic subgroup. Finally, rather than measuring complex concepts such as social determinants with one question, this study reflects multiple aspects of complex concepts through scales and identifies groups of respondents with similar perspectives by analyzing their response patterns. To answer our research questions fully, analyses were designed to handle both adjustment and correlation across variables.

\section{Methods}

\section{Study aims}

This paper contributes to our understanding of the American mindset around social determinants of health and health equity with recent data from the 2018 National Survey of Health Attitudes (NSHA) [24], a survey developed and fielded by the Robert Wood Johnson Foundation (RWJF) and the RAND Corporation, to address two aims:

1. To examine what factors people in the U.S. think drive health, whether and how levels of understanding vary, and how these levels of understanding may differ by demographic characteristics.

2. To assess the relationship between someone's level of understanding of the drivers of health and their beliefs about the importance of achieving health equity in the U.S., with attention to demographic differences.

\section{Survey}

This study uses data from the 2018 NSHA. The NSHA was developed as part of RWJF's efforts to understand national perspectives related to the Culture of Health, with a primary focus on the action area making health a shared value $[24,25]$. Relevant drivers of making health a shared value include the value of health; the role that social determinants of health play in influencing health; and a shared sense of community to influence health. These drivers were operationalized through the following measures: whether respondents (1) recognized the influence of behavioral, social, physical and other factors on health, (2) had an awareness of the role of community in health, and (3) believed in the importance and fairness of health equity.

Respondents were recruited from two nationally representative online panels: the RAND American Life Panel (ALP) and the KnowledgePanel (which was administered at the time by GfK Custom Research but has since been sold to Ipsos). Both panels: (1) are nationally representative Internet panels whose members are recruited via probability-based sampling methods; (2) provide computers and Internet connections for respondents who do not have them at the time of panel recruitment; (3) compensate respondents for their participation; and (4) collect and provide demographic information about respondents $[26,27]$. The implementation of the survey was identical in the two panels. We fielded the survey using the ALP because of the rich historical data collected through that panel that can be linked to new data collection [26, 27]. These historical data include not only the previous survey that we ran in the ALP in 2015, but also any other surveys previous run in the ALP. However, to boost sample size, we also conducted the survey in the KnowledgePanel. In previous work, we compared responses across the two panels $[24,25]$. To test the feasibility of combining the two samples, we investigated whether there were systematic differences between responses to the two surveys, after controlling for demographic characteristics, and found no meaningful differences.

Data were collected between July 11 and August 30, 2018. The two survey efforts combined resulted in a final total sample of 7187 completed surveys: 2479 from the ALP and 4708 from the KnowledgePanel. We used data from a subset of respondents (7077) who answered the survey items on drivers of health and well-being and health equity.

\section{Measures \\ Beliefs about drivers of health and well-being and sense of community health}

Respondents reviewed a list of 17 items, each representing a known driver of health and well-being. These items covered a range of topics, including health-related behaviors, 
access to health care, knowledge about health, and social and place-based factors (e.g., employment, housing quality) and were based on existing survey questions about drivers of health developed by Robert and Booske (2011) [28]. For each item, respondents were asked on a 5-point scale what effect that driver has on health and well-being, with 1 representing "no effect" and 5 representing a "very strong effect." We dichotomized each item by grouping responses of 4 and 5 into one category representing respondents believing the driver to have a strong effect and responses of 1-3 into a category representing respondents not believing the driver to have a strong effect. An additional set of four items asked respondents about their beliefs about their community's ability to drive health, which were adapted from the Sense of Community Index (SCI) [29, 30]. We dichotomized each item by grouping responses "mostly" and "completely" into one category representing respondents believing their community does have the ability to drive health and responses "somewhat" and "not at all" into a category representing respondents not believing their community has the ability to drive health.

\section{Beliefs about health equity}

A review of existing survey questions on topics related to health disparities, drivers of health, and social determinants found few existing survey questions about health equity beliefs. One previous study had surveyed U.S. residents about their views on health equity and these items were adapted for this survey by research team members with experience in health equity theory and survey development [16]. Three questions about health equity beliefs were included in order to assess performance of different types of wording. In particular, we kept the language broadly inclusive and focused on concepts of fairness, justice, and equality. To assess beliefs about health equity, respondents were asked to place a priority value to a set of three statements about opportunities to be healthy:

1. "Making sure that the disadvantaged have an equal opportunity to be healthy."

2. "It would be unfair if some people had more of an opportunity to be healthy than other people."

3. "Our society needs to do more to make sure that everyone has 'an equal'/ 'a fair and just' opportunity to be healthy."

Questions 1 and 2 were included in a previous survey conducted and tested by NORC [16]. Question 3 was modified from a question included in the American $\mathrm{Na}-$ tional Election study on equal opportunities in general, to focus specifically on opportunities to be healthy [31]. Response options for item 1 were a 3-point scale: top priority, important but not a top priority, or not a priority at all. Response options for items 2 and 3 were a 5-point scale where 1 represented "strongly disagree" and 5 represented "strongly agree." For item 3, the item's wording was randomized in presentation to respondents as either "an equal" or "a fair and just opportunity." There were no differences in distribution of response patterns between the two presentations, so for analytic purposes, they were combined into one item. All three items were dichotomized by separating responses at the highest level of endorsement from the other levels for each item. Results of this study show consistency in the performance of all three items based on similar response patterns and associations with other survey items.

\section{Factor analyses}

We assessed the 21 items representing health drivers individually and then grouped them into factors to facilitate data analysis and assessing broader linkages between drivers of health and health equity. We first conducted an exploratory factor analysis (EFA) on the items and identified three factors, which we labeled traditional health influencers (THI), social and economic determinants of health $(\mathrm{SDoH})$, and sense of community health $(\mathrm{SoC})$ (see Results for more information). We followed up with a confirmatory factor analysis (CFA) to examine factor loading patterns with the goal of defining groupings of items with minimum cross loadings. Model fit was evaluated for EFA and CFA to find the best fitting model for the items. Items were deleted from future analyses if they did not contribute to the differentiation of responses.

\section{Latent class analysis (LCA)}

We used LCA to identify participant groups with similar patterns of response to the 21 items and three factors. Models specifying up to 5 classes were run and compared on their ability to tease out distinct patterns of response aligned to factors and fit statistics, including Akaike's information criteria (AIC) [32] and Bayesian Information Criterion (BIC) [33]. These statistics assess model fit while penalizing the number of estimated parameters. Yang (2006) [34] demonstrated adjusted BIC [35] to be the best indicator of the information criteria considered for LCA. As more classes were extracted, the model fit improved until the adjusted BIC stabilized and the number of classes was still interpretable. Respondents were assigned to classes based on their highest probability of membership [33]. The classes were mutually exclusive.

\section{Factor mixture modeling (FMM)}

FMM is a type of structural equation modeling that allows the simultaneous inclusion of factor analysis (continuous) and LCA (categorical) [36] in the estimation process $[37,38]$. FMM also accommodates the estimation of 
covariates on both latent factors and latent classes in the same modeling step. FMM can identify profiles in the sample while simultaneously estimating a latent factor model for each profile. For simplicity, we assumed the same latent factor model for each profile (i.e., constraining all factor loading estimates to be the same across the latent classes). The inputs used for FMM were: 1) the predefined number of factors from EFA, 2) how each factor was defined by the 21 items from CFA, and 3) the number of latent classes from the best solution in LCA.

We examined how observable demographics differed across latent classes using FMM. We incorporated basic demographics such as respondent's age, gender, race/ethnicity, marital status, employment status, education level, household size, household income, health insurance status, urbanicity, and residence in a large city. Marital status was dichotomized as married or living with a partner vs. separated, divorced, widowed, or never married. Employment status was dichotomized as working or not working. Household size comprised three categories: one, two, or three or more people living in a household. Household income was converted into a five-level categorical scale. Race consisted of the following categories: non-Hispanic White, non-Hispanic Black, Hispanic, Asian, and nonHispanic all other races. Education level was defined as: less than high school; high school diploma; some college or Associate's degree; and Bachelor's degree or more.

\section{Logistic regression}

Latent classes from FMM results were used to examine how latent class membership and observable demographic characteristics influenced respondents' beliefs about health equity.

Latent class membership and demographics were used as predictors in three separate logistic regressions, each using one of the three belief statements as the dependent variable to identify which characteristics predict endorsement of health equity beliefs. We modeled the probability of endorsing the highest response category, i.e., the response option "top priority" for belief statement 1 and the response option "strongly agree" for belief statements 2 and 3. All analyses in this paper were carried out using Mplus V8 [39] with the exception of the logistic regressions, conducted using Stata MP 16 [40].

\section{Results}

Aim 1. Factors driving health

Identifying factors that drive health: traditional health influencers, social determinants of health, and sense of community health

Of 21 items used for EFA and CFA, we retained 18 items based on model fit and reasonable loading. The three items dropped were smoking, genetic makeup inherited from parents, and having health insurance.
Three factors were extracted from these 18 items to represent health drivers: Factor 1 (F1) represents Traditional Health Influencers (THI) and is defined by four indicators; Factor 2 (F2) represents Social and Economic Determinants of Health $(\mathrm{SDoH})$ and is defined by ten indicators; Factor 3 (F3) represents Sense of Community Health $(\mathrm{SoC})$ and is defined by four indicators.

FMM results for factor loadings (Table 1) show how each factor is represented by its composite indicators. Loading values are all moderate to high. Among these, the highest loading indicator for F1 (THI) is access to affordable healthcare, for $\mathrm{F} 2(\mathrm{SDoH})$ is housing quality, and for F3 (SoC) is endorsement of the statement my community works together to make positive change for health.

Revealing varied comprehension of drivers of health: classes of respondents by patterns of indicator and factor endorsement

FMM results for LCA specify "classes" of respondents based on their pattern of endorsement of health drivers.

Table 1 Factor loadings for each factor driving health, assuming fixed values across latent classes

\begin{tabular}{|c|c|}
\hline Factors and composite indicators & $\begin{array}{l}\text { Standardized } \\
\text { loadings }\end{array}$ \\
\hline \multicolumn{2}{|l|}{ F1: Traditional Health Influencers } \\
\hline 1. Access to affordable healthcare & 0.66 \\
\hline 2. Stress & 0.52 \\
\hline 3. Knowledge about health & 0.63 \\
\hline $\begin{array}{l}\text { 4. Personal health practices other } \\
\text { than smoking }\end{array}$ & 0.51 \\
\hline \multicolumn{2}{|l|}{ F2: Social Determinants } \\
\hline 5. Having a job & 0.52 \\
\hline $\begin{array}{l}\text { 6. Neighborhood options for } \\
\text { healthy food and exercise }\end{array}$ & 0.59 \\
\hline 7. Amount of social support & 0.59 \\
\hline $\begin{array}{l}\text { 8. Physical environment such as } \\
\text { clean air or water }\end{array}$ & 0.65 \\
\hline 9. Income & 0.61 \\
\hline 10. Community safety & 0.66 \\
\hline 11. Housing quality & 0.71 \\
\hline 12. Education & 0.58 \\
\hline 13. Where a person lives & 0.64 \\
\hline 14. Race/Ethnicity & 0.46 \\
\hline \multicolumn{2}{|l|}{ F3: Sense of Community Health } \\
\hline $\begin{array}{l}\text { 15. My community can work } \\
\text { together to improve its health }\end{array}$ & 0.83 \\
\hline $\begin{array}{l}\text { 16. My community has the } \\
\text { resources to improve its health }\end{array}$ & 0.69 \\
\hline $\begin{array}{l}\text { 17. My community works together } \\
\text { to make positive change for health }\end{array}$ & 0.84 \\
\hline $\begin{array}{l}\text { 18. I know my neighbors will help } \\
\text { me stay healthy }\end{array}$ & 0.78 \\
\hline
\end{tabular}


Figure 1 presents the four extracted latent classes. The $\mathrm{x}$-axis presents the indicators in the following order (or see Table 1): indicators 1-4 define THI; 5-14 define $\mathrm{SDoH}$; and 15-18 define SoC.

Each class is represented by a set of color-coded lines. The dots on the lines correspond to conditional probabilities (on the $y$-axis) of endorsing each indicator given class membership. For example, those in class 3 have approximately a $77 \%$ probability of endorsing indicator 1 ("access to affordable health care") as being an important or very important driver of health.

Each class exhibits a distinctive pattern of indicator and factor endorsement. Class 4 is defined by a near $0 \%$ endorsement of indicators for both THI and SDoH. Classes 1, 2, and 3 all have relatively high endorsement of indicators defining THI (greater than $70 \%$ probability for all indicators). Classes 1 and 2 are high endorsers of SDoH (greater than $70 \%$ probability for most indicators), but probability of class 3 endorsement of $\mathrm{SDoH}$ indicators generally hovers around 50\%. Notably, for all 3 groups, indicator 14, which assesses race/ethnicity as a driver of health, was endorsed at a substantially lower percentage for classes 1, 2, and 3 compared to endorsement of other $\mathrm{SDoH}$ indicators. In class 2, all other $\mathrm{SDoH}$ indicators were endorsed at $70 \%$ of the sample or higher, but race/ethnicity was endorsed at approximately $45 \%$. For SoC indicators, classes 1,3 , and 4 endorsed them at low percentages (all indicators under were 15\%). Class 2 endorsed SoC indicators at a higher percentage (approximately 15-25\%) compared to the other classes, though these percentages are still low.

Examining the distribution of survey respondents within classes, class 3 is the largest class at $88.3 \%$ of the sample. This class represents high endorsers of THI, moderate endorsers of SDoH, and low endorsers of SoC. As the majority of respondents are in class 3 , it was used as the reference group in later analyses. All other classes contain very small percentages of respondents: class 1 , 5.7\%; class 2, 3.2\%; class 4, 2.8\%. Respondents of class 2 are of particular interest as they are high endorsers of both $\mathrm{THI}$ and $\mathrm{SDoH}$, and the highest endorsers of SoC, potentially representing the group with the most comprehensive understanding of the factors that drive health.

\section{Examining variation in class membership by demographics}

We examined how these four classes differed by key demographics. Table 2 presents summary statistics of demographics by class.

\section{Class 1}

LCA results indicated that Class 1 respondents were, on average, high endorsers of both THI and SDoH as drivers of health (though not SoC). Compared to other

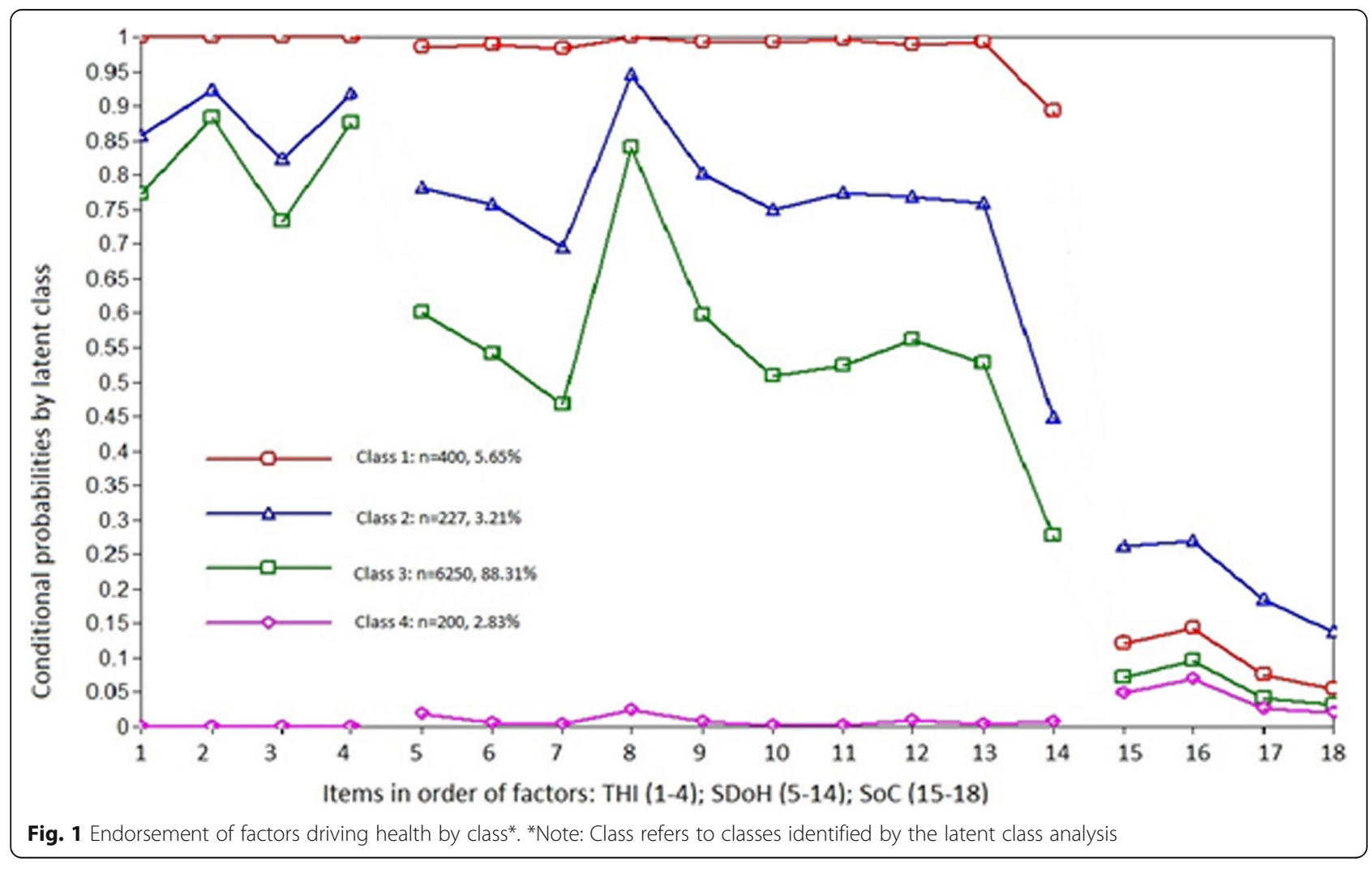


Table 2 Demographic characteristics of respondents by class ${ }^{a}$

\begin{tabular}{|c|c|c|c|c|}
\hline & Class 1 & Class 2 & Class 3 & Class 4 \\
\hline Percent of total sample & $5.7 \%$ & $3.2 \%$ & $88.3 \%$ & $2.8 \%$ \\
\hline Age mean (SD) & $57.0(15.7)$ & $44.4(15.1)$ & $54.2(15.8)$ & $43.3(16.7)$ \\
\hline$\%$ Male & $39.3 \%$ & $64.1 \%$ & $46.2 \%$ & $50.8 \%$ \\
\hline$\%$ Married or living with partner & $55.6 \%$ & $55.9 \%$ & $65.4 \%$ & $54.3 \%$ \\
\hline \% Unemployed & $7.9 \%$ & $5.2 \%$ & $4.6 \%$ & $12.1 \%$ \\
\hline$\%$ Some college or more & $67.2 \%$ & $46.3 \%$ & $74.0 \%$ & $39.2 \%$ \\
\hline$\%$ Household size of 1 person & $23.4 \%$ & $22.1 \%$ & $20.3 \%$ & $20.1 \%$ \\
\hline$\%$ Living in rural area & $17.4 \%$ & $25.7 \%$ & $13.1 \%$ & $10.6 \%$ \\
\hline$\%$ Living in large city & $69.2 \%$ & $39.0 \%$ & $54.0 \%$ & $61.8 \%$ \\
\hline$\%$ Has insurance & $92.4 \%$ & $93.4 \%$ & $94.3 \%$ & $85.0 \%$ \\
\hline \multicolumn{5}{|l|}{ Household income in dollars } \\
\hline Less than 10,000 & $2.5 \%$ & $22.8 \%$ & $3.5 \%$ & $16.6 \%$ \\
\hline 10,000 to 24,999 & $13.2 \%$ & $33.1 \%$ & $10.3 \%$ & $17.6 \%$ \\
\hline 25,000 to 49,999 & $21.3 \%$ & $23.5 \%$ & $21.0 \%$ & $23.6 \%$ \\
\hline 50,000 to 74,999 & $18.6 \%$ & $10.3 \%$ & $19.0 \%$ & $16.1 \%$ \\
\hline 75,000 to 99,999 & $11.4 \%$ & $2.2 \%$ & $13.3 \%$ & $8.0 \%$ \\
\hline 100,000 or more & $33.3 \%$ & $8.1 \%$ & $32.9 \%$ & $18.1 \%$ \\
\hline \multicolumn{5}{|l|}{ Race } \\
\hline Black & $24.2 \%$ & $33.1 \%$ & $7.4 \%$ & $18.1 \%$ \\
\hline Hispanic & $19.4 \%$ & $27.2 \%$ & $12.2 \%$ & $20.6 \%$ \\
\hline Non-Hispanic White & $51.3 \%$ & $29.3 \%$ & $74.2 \%$ & $52.8 \%$ \\
\hline Asian & $4.1 \%$ & $5.2 \%$ & $3.0 \%$ & $4.5 \%$ \\
\hline Other & $1.0 \%$ & $5.2 \%$ & $3.2 \%$ & $4.0 \%$ \\
\hline
\end{tabular}

${ }^{a}$ Note: Class refers to classes identified by the latent class analysis

classes, class 1 respondents were least likely to be male (39\%) and most likely to be living in large cities (69\%). They had the second highest percentage of respondents with at least some college (67\%) after class $3(74 \%)$. They had higher household incomes compared to other classes, i.e., they have the highest percentage of respondents in the highest income category $(\$ 100,000+, 33 \%)$ and the lowest percentage of respondents in the lowest income category (less than $\$ 10,000,2.5 \%$ ). Class 1 had the second highest percentage of Black respondents (24\%) after class 2 and non-Hispanic whites were the majority (51\%) in this class.

\section{Class 2}

Class 2 respondents were identified in the LCA as having the broadest comprehension about what drives health, as evidenced by high endorsement of THI and $\mathrm{SDoH}$, as well as a distinctly higher endorsement of SoC, compared to other classes. Class 2 respondents were more likely to be male (64\%), living in rural areas (25.7\%), and least likely to be living in large cities (39\%). They had lower household incomes compared to other classes, i.e., they had the highest percentage of respondents in the lowest income category (less than $\$ 10,000,22.8 \%$ ) and the lowest percentage of respondents in the highest income category $(\$ 100,000+, 8 \%)$. Class 2 had the highest percentages of Black (33\%) and Hispanic (27\%) respondents of all classes and class 2 is the only class in which nonHispanic whites were not the majority (29\%).

\section{Class 3}

LCA results indicated that most of the sample was represented in class $3(88 \%)$ and they were high endorsers of THI but had lower likelihood of endorsing SDoH and SoC. Class 3 had the highest percentages of married respondents $(65 \%)$ and respondents having at least some college $(74 \%)$ education. About one-third of them were in the highest household income category, similar to class 1 . A vast majority of respondents in this category were non-Hispanic white (74\%), which is higher than all other classes.

\section{Class 4}

Class 4 were low endorsers of all three drivers of health. They had the highest percentage among all classes of unemployed respondents at $12.1 \%$. They had moderate 
to low household incomes with $58 \%$ falling into the lowest three income categories $(\$ 49,999$ and lower). NonHispanic whites were the majority (53\%) in this class.

\section{Aim 2. Association between understanding of health drivers and health equity views}

Examining differences in perceptions of the importance of health equity, we observed differences by demographics and class membership across equity beliefs (Table 3).

Table 3 provides the average partial effect of each independent variable on the probability of endorsing each equity belief. A separate logistic regression was run for each belief. For a categorical variable, the average partial effect is interpreted as the average difference in the probability of endorsing the belief item for that category compared to the reference group, where the average is over the possible values of all the other covariates. For a continuous variable, the average partial effect represents the average effect of a one unit increase in the variable on the probability (on a scale of 0 to 1 ) of endorsing the belief item, where the average is over all the possible values of all the other covariates, including the continuous

Table 3 Average partial effects from regressions of demographics (independent variables) on health equity beliefs (dependent variables)

\begin{tabular}{|c|c|c|c|}
\hline $\begin{array}{l}\text { Health equity beliefs } \\
\text { (dependent variable) }\end{array}$ & $\begin{array}{l}\text { 1. Making sure that the } \\
\text { disadvantaged have an } \\
\text { equal opportunity to be } \\
\text { healthy }\end{array}$ & $\begin{array}{l}\text { 2. It would be unfair if some } \\
\text { people had more of an opportunity } \\
\text { to be healthy than other people }\end{array}$ & $\begin{array}{l}\text { 3. Our society needs to do more } \\
\text { to make sure that everyone has } \\
\text { 'an equal'/ 'a fair and just' } \\
\text { opportunity to be healthy }\end{array}$ \\
\hline $\mathrm{N}, \%$ endorsing highest response category & $3200,44.7 \%$ & $2236,31.3 \%$ & $2920,40.8 \%$ \\
\hline \multicolumn{4}{|l|}{ Class membership $($ ref $=$ class 3$)$} \\
\hline class 1 & $0.24^{*}$ & $0.20^{*}$ & $0.25^{*}$ \\
\hline class 2 & $0.24^{*}$ & $0.14^{*}$ & $0.24^{*}$ \\
\hline class 4 & $-0.22^{*}$ & $-0.23^{*}$ & $-0.30^{*}$ \\
\hline Age & $0.001^{*}$ & $0.002^{*}$ & $0.002^{*}$ \\
\hline \multicolumn{4}{|l|}{ Education (ref = high school diploma) } \\
\hline Less than high school & 0.0 & -0.01 & 0.04 \\
\hline Some college, associate's degree & $0.06^{*}$ & $0.06^{*}$ & $0.07^{*}$ \\
\hline Bachelor's degree or more & $0.11^{*}$ & $0.07^{*}$ & $0.13^{*}$ \\
\hline \multicolumn{4}{|l|}{ Household size (ref = 2) } \\
\hline Household size 1 person & $-0.05^{*}$ & -0.02 & -0.02 \\
\hline Household size 3 or more & -0.01 & -0.00 & -0.01 \\
\hline \multicolumn{4}{|c|}{ Household income (ref = between $\$ 75,000$ and $\$ 124,999$ ) } \\
\hline$<\$ 24,999$ & $0.18^{*}$ & $0.12^{*}$ & $0.16^{*}$ \\
\hline$\$ 25,000$ to $\$ 49,999$ & $0.06^{*}$ & $0.08^{*}$ & $0.07^{*}$ \\
\hline$\$ 50,000$ to $\$ 74,999$ & $0.04^{*}$ & $0.04^{*}$ & $0.04^{*}$ \\
\hline$>\$ 125,000$ & -0.03 & -0.03 & -0.03 \\
\hline Has insurance (ref = none) & 0.01 & -0.02 & -0.001 \\
\hline Being male (ref = female) & $-0.14^{*}$ & $-0.08^{*}$ & $-0.09^{*}$ \\
\hline Married (ref = not married) & $-0.05^{*}$ & -0.02 & -0.02 \\
\hline Unemployed (ref = not unemployed) & 0.02 & $0.05^{*}$ & $0.07^{*}$ \\
\hline \multicolumn{4}{|l|}{ Race/ethnicity (ref = Non-Hispanic White) } \\
\hline Black & $0.17 *$ & $0.16^{*}$ & $0.15^{*}$ \\
\hline Hispanic & $0.13^{*}$ & $0.08^{*}$ & $0.09^{*}$ \\
\hline Asian & $-0.12^{*}$ & -0.05 & -0.004 \\
\hline Other & 0.04 & $0.08^{*}$ & 0.04 \\
\hline $\begin{array}{l}\text { Living in rural area (ref }=\text { not living in rural } \\
\text { area) }\end{array}$ & -0.07 & $-0.04^{*}$ & $-0.09^{*}$ \\
\hline $\begin{array}{l}\text { Living in large city (ref = not living in large } \\
\text { city) }\end{array}$ & -0.001 & 0.01 & $0.03^{*}$ \\
\hline
\end{tabular}

Note: * $p$ values $<.05$ 
variable. Intuitively, the average partial effects can be interpreted in a similar manner to the coefficients in a linear probability model. For example, looking at the effect of gender on belief 1 , the estimate of -0.14 for gender indicates that on average, the probability that men endorsed belief 1 is 0.14 points lower than the probability that women endorsed this item, where the average is over all the possible values of the other covariates. Men are, on average, 0.14 points less likely to think this item is important compared to women.

Across three health equity beliefs, we observed some consistent endorsement patterns. Respondents who were more likely to endorse all three beliefs tended to be female, older, Black or Hispanic (vs. non-Hispanic white), have more education (some college or Bachelor's degree compared to those with only a high-school degree), and have lower household incomes (less than $\$ 74$, 999 vs. between $\$ 75,000$ and $\$ 124,999)$. We also found that respondents who strongly agreed with beliefs 2 and 3 were more likely to be unemployed and living in nonrural areas.

Class membership was examined in the logistic regression. We found the same endorsement response patterns across all three health equity beliefs by class in terms of direction of association and significance. Class 2 on average, had a significantly higher probability (.24 percentage points) of endorsing belief 1 compared to class 3 (the reference group), and in previous analyses, class 2 was found to have the highest comprehension of health drivers overall, strongly endorsing THI and SDoH and endorsing $\mathrm{SoC}$ higher than the other classes. Class 2 had similar patterns of significantly higher probabilities of endorsement of the two other beliefs compared to class 3 (.24 and .14, respectively). Members of class 1 had, on average, a significantly higher probability (.24 percentage points) of endorsing belief 1 compared to members of class 3 , and this pattern was similar for the other beliefs. Members of class 1 were also strong endorsers of both $\mathrm{THI}$ and $\mathrm{SDoH}$ in previous analyses. By contrast, class 4 had, on average, a significantly lower probability $(.22 \%$ points) of endorsing belief 1 compared to class 3 and 4's endorsement patterns and were similar for the other beliefs. They were also weak endorsers of any health driver factors in previous analyses.

\section{Discussion}

This study contributes to the evidence around Americans' understanding of the factors that impact health, as well as offers new insight into the extent to which they value health equity and differences in these beliefs by subgroup. Despite efforts by the public health community, equity advocates, and a growing coalition of nonprofits, governments, and foundations, our research shows that the dominant narrative about drivers of health and health equity is powerful and resistant to change: Most Americans believe that health is predominantly influenced by individual behaviors and access to health care, as opposed to structural and social factors, and health equity is not a widespread priority.

Findings from the latent class analysis show that the majority of Americans surveyed in 2018 still lack knowledge about the social determinants of health or the role of community on health outcomes. Nearly $90 \%$ of respondents were members of a class (class 3) characterized by high endorsement of THI (including access to health care, stress, and health behaviors), but lower endorsement of $\mathrm{SDoH}$ (including having a job, neighborhood options for healthy food and exercise, social support, housing quality, and race/ethnicity), and very low endorsement of SoC (including beliefs that the community can work together to improve its health, has the resources to improve its health, and works together to make positive changes for health). Hallmarks of belonging in this class are that members were predominantly White $(74 \%)$, educated (74\% reporting at least some college education), and high-income (nearly half the members reported annual household incomes in the highest two categories). Each of these percentages were highest for this class compared to the other three classes. In contrast, the class found to have the broadest comprehension about what drives health (class 2), as evidenced by high endorsement of both THI and $\mathrm{SDoH}$ and the highest endorsement of $\mathrm{SoC}$ of all classes, was also the class representing only $3.2 \%$ of respondents. Members of this class were the most racially and ethnically diverse out of all classes, with the highest percentages of Black (33\%), Hispanic (27\%), and Asian (5.2\%) members. This class was also the poorest, with $56 \%$ of individuals reporting a household income in the lowest two categories. The stark differences between these two classes in terms of their understanding of what drives health suggest that lived experiences based on race and/or income may be instructive about how $\mathrm{SDoH}$ and $\mathrm{SoC}$ can impact health.

Findings from the logistic regression examining health equity beliefs echoed previous findings and revealed new ones $[19,21,22]$. None of the three health equity beliefs received over $50 \%$ endorsement of the highest response category. In fact, only $31 \%$ of the sample strongly agreed that it would be unfair if some people had more of an opportunity to be healthy than other people. Respondents endorsing all three health equity beliefs tended to be female, older, Black or Hispanic, have more education, and have lower incomes. The relationship between income level and perceived importance of health equity showed a dose-response pattern in which the lower a respondent's income level, the higher the likelihood of perceiving health equity to be important (observed across 
all three beliefs). In terms of class membership, class 2 (which had the broadest understanding of what drives health) had significantly higher probabilities of endorsing all three health equity beliefs compared to the reference class (class 3). Class 1 shared the same pattern of health equity belief endorsement as class 2; class 1's similarities to class 2 include racial and ethnic diversity (24\% Black and 19\% Hispanic representation) and high endorsement of both THI and SDoH as drivers of health. The differences between these two groups are also important to understand. Class 1 is overall richer (45\% reporting in two highest income categories) and more educated (20\% more members reporting some college education) than class 3 . Therefore racial/ethnic minority status was the factor most strongly associated with understanding of health drivers and the perceived value of health equity, even beyond the role of income, which was also significant.

These findings also have implications for how we understand the roots of beliefs about the $\mathrm{SDoH}$ and health equity, and the role of demographics in those beliefs. We found evidence that those who may have experienced disadvantage as a result of their race or income may more readily connect social and economic circumstances to health-related challenges. On the flipside, those who experience relative privilege based on their sociodemographic characteristics may fall back on cultural schemas regarding the role of individual behaviors, rather than considering structural influences [41], and prior research shows they may even actively oppose efforts to level the playing field, citing "reverse discrimination" [42]. Prior to this work, there has been limited research on the role of demographics and lived experience on beliefs about factors that determine health and values of health equity.

As with any study, there are important limitations to note. The NSHA is being fielded approximately every 3 years, but this paper only reports on the 2018 survey. As such, it will be useful to look at the relationship between health mindset and understanding and health equity, if and how that evolves over time, and why. We are potentially living through an inflection point when it comes to demands for racial equity, and it will be valuable to continue to track health equity beliefs among this nationally representative sample in future iterations of the survey. The health equity belief items used in this survey have been used previously and adapted for this study; however, further use of these items would produce more evidence for their construct validity. For this study, we used all three items in our analyses to better understand their performance. The results as shown in Table 3 indicate that these items performed consistently across a range of demographic predictors, suggesting that they were all understood similarly by respondents of different backgrounds. Additionally, the items we used to capture perspectives on health equity are mostly based on broad beliefs, and we do not know yet if different groups might respond differently to more specific aspects of health equity, such as race, income, class, etc. While we built on established scales of SDoH recognition, the items we used to assess $\mathrm{SoC}$, while adapted from existing scales, are comparatively new given the limited research on this topic.

\section{Conclusion}

Increasing inequities across health, social, and economic outcomes, which have only been highlighted by the impacts of the COVID-19 pandemic on low-income communities and communities of color, and widespread social unrest related to the topic of race, underscore the urgency of influencing Americans' beliefs in the importance of achieving health equity. Many perceive that public sentiment has been shifting over the past decade, through movements like Occupy Wall Street, Black Lives Matter, and others, toward values of equity and dismantling historically unjust systems that have perpetuated disparate health outcomes. However, this research suggests that an understanding of specific mechanisms of inequity across all sectors, including health, may have not yet penetrated the American mindset. Without a more detailed understanding of the issues driving inequality, some Americans will be unable to participate fully in public discourse about how to make policy, economic, and system-based changes needed to shift the U.S. toward equitable outcomes.

And a current understanding of true public sentiment is important because issues looked upon favorably by the public can drive policy change (e.g., federally recognized marriage equality, where evolving positive views and widespread publicity about states' positions on the issue played roles in bringing a case to the Supreme Court [43]). Based on what we know about the factors influencing health--factors related to the places where people live, work, and play--we must make systems more fair as a critical part of achieving health equity. People need to know what truly drives health (e.g., social determinants) so that they can understand how and why the U.S. has not yet achieved health equity. To understand the role of social determinants on health is to see that the real levers for improving health equity are through systems change, as opposed to individual behaviors or health care interventions alone. Public opinion about the impact of systems in health, the perceived unfairness of injustice embedded in those systems, and consequently, the level of public support for changing systems so that they improve health, all contribute to policy makers' motivations to change those policies [28]. Moreover, systems change demands leadership from individuals who are well-versed in the interaction across health care, 
criminal justice, social services, education, and neighborhood influences on health. The perceived legitimacy of this leadership is partially determined by the predominant narratives we observe and our ability to transcend the boundaries we have established between individuals of different disciplines, political parties, and stations in life. As our research shows, siloing the call for health equity in the public health and social justice sectors has proven relatively futile in moving public opinion about the SDoH and importance of health equity. If our country is to realize the true change that recent calls to action have demanded, it will be critical to heed these insights about the dominant mindset in the U.S.

\begin{abstract}
Abbreviations
AIC: Akaike's information criteria; ALP: American Life Panel; BIC: Bayesian Information Criterion; CFA: confirmatory factor analysis; EFA: exploratory factor analysis; F1: Factor 1; F2: Factor 2; F3: Factor 3; FMM: Factor mixture modeling; LCA: latent class analysis; NSHA: National Survey of Health Attitudes; RWJF: Robert Wood Johnson Foundation; SDoH: Social determinants of health; SoC: Sense of community health; THI: Traditional health influences
\end{abstract}

\section{Acknowledgements}

We thank Dr. Jessie Coe for her analytic support and Ms. Martina Todaro for her careful review of the paper.

\section{Authors' contributions}

$\mathrm{VT}$ interpreted the results of the analysis and was a major contributor in writing the manuscript. LWM performed the literature review and was a major contributor in writing the manuscript. WH performed the statistical analyses and interpreted the results. LM reviewed and edited the manuscript. KC managed the survey data, consulted on analyses, and reviewed the manuscript. CM reviewed and edited the manuscript. AC reviewed and edited the manuscript. All authors read and approved the final manuscript.

\section{Funding}

This research was funded by the Robert Wood Johnson Foundation (Award no. 74430). The funding body offered input on the study design and interpretation of data, but ultimately the RAND study team had final determination of all research design, analysis, and interpretation choices. The manuscript was written by the RAND study team and a representative of the funding body reviewed it.

\section{Availability of data and materials}

Data were collected by the research team and have been deposited at ICPS R. Data are located at https://www.icpsr.umich.edu/ and can be accessed by registering to access study data.

\section{Ethics approval and consent to participate}

Data collection was approved by RAND's Human Subjects Protection Committee, which acts as RAND's Internal Review Board. Survey participants receive consent materials once per year consenting to participate in surveys from the ALP or the KnowledgePanel and are given the right to skip any survey or question. For both panels, consent to participate was obtained via website confirmation (Participants clicked to consent.).

\section{Consent for publication}

Not applicable.

\section{Competing interests}

A representative of the funding body (the Robert Wood Johnson Foundation) reviewed and edited the manuscript, but the RAND study team had final determination over the research design, analysis, interpretation, and write-up (see "Funding" declarations).

\section{Author details}

'Patient-Centered Outcomes Research Institute (PCORI), Washington, D.C., USA. ${ }^{2}$ RAND Corporation, 4570 Fifth Avenue, Suite 600, Pittsburgh, PA 15213, USA. ${ }^{3}$ Robert Wood Johnson Foundation, Princeton, NJ, USA.

Received: 13 August 2020 Accepted: 6 January 2021

Published online: 21 January 2021

\section{References}

1. WHO Commission on Social Determinants of Health. Closing the gap in a generation: health equity through action on the social determinants of health: Commission on Social Determinants of Health final report. Geneva: World Health Organization; 2008.

2. Horowitz JM, Igielnik R, Kochhar R. Trends in income and wealth inequality: Pew Reseach Center; 2020. Available from: https://www.pewsocialtrends. org/2020/01/09/trends-in-income-and-wealth-inequality/\#fn-27657-9. Accessed 10 Dec 2020.

3. Bailey ZD, Krieger N, Agénor M, Graves J, Linos N, Bassett MT. Structural racism and health inequities in the USA: evidence and interventions. Lancet. 2017;389(10077):1453-63.

4. Anand S. The concern for equity in health. J Epidemiol Community Health. 2002;56(7):485.

5. Dubay LC, Lebrun LA. Health, behavior, and health care disparities: disentangling the effects of income and race in the United States. Int J Health Serv. 2012;42(4):607-25.

6. Bond MJ, Herman AA. Lagging life expectancy for black men: a public health imperative. Am J Public Health. 2016;106(7):1167-9.

7. Remington $\mathrm{PL}$, Catlin BB, Gennuso KP. The county health rankings: rationale and methods. Popul Health Metrics. 2015;13(1):11.

8. Nellis A. The color of justice: racial and ethnic disparity in state prisons. Sentencing Project; 2016.

9. Wilson V. Racial disparities in income and poverty remain largely unchanged amid strong income growth in 2019. Economic Policy Institute; 2020. Available from: https://www.epi.org/blog/racial-disparities-in-income-and-povertyremain-largely-unchanged-amid-strong-income-growth-in-2019/. Accessed 10 Dec 2020.

10. Marmot M, Allen JJ. Social determinants of health equity. Am J Public Health. 2014;104(Suppl 4):S517-9.

11. Townsend B, Friel S, Freeman T, Schram A, Strazdins L, Labonte R, et al. Advancing a health equity agenda across multiple policy domains: a qualitative policy analysis of social, trade and welfare policy. BMJ Open. 2020;10(11):e040180-e.

12. Penman-Aguilar A, Talih M, Huang D, Moonesinghe R, Bouye K, Beckles G. Measurement of Health Disparities, Health Inequities, and Social Determinants of Health to Support the Advancement of Health Equity. J Public Health Manag Pract. 2016;22 Suppl 1(Suppl 1):S33-42.

13. Baum FE, Bégin M, Houweling TA, Taylor S. Changes not for the fainthearted: reorienting health care systems toward health equity through action on the social determinants of health. Am J Public Health. 2009;99(11): 1967-74.

14. Barten F, Mitlin D, Mulholland C, Hardoy A, Stern R. Integrated approaches to address the social determinants of health for reducing health inequity. J Urban Health. 2007;84(1):164-73.

15. Booske BC, Robert SA, Rohan AM. Awareness of racial and socioeconomic health disparities in the United States: the national opinion survey on health and health disparities, 2008-2009. Prev Chronic Dis. 2011;8(4):A73.

16. Bye $L$, Ghirardelli A, Fontes A. Promoting health equity and population health: how Americans' views differ. Health Aff. 2016;35(11):1982-90.

17. Niederdeppe J, Bu QL, Borah P, Kindig DA, Robert SA. Message design strategies to raise public awareness of social determinants of health and population health disparities. Milbank Q. 2008;86(3):481-513.

18. Robert SA, Booske BC, Rigby E, Rohan AM. Public views on determinants of health, interventions to improve health, and priorities for government. Wis Med J. 2008;107(3):124.

19. Rigby E, Soss J, Booske BC, Rohan AMK, Robert SA. Public responses to health disparities: how group cues influence support for government intervention*. Soc Sci Q. 2009;90(5):1321-40.

20. Baum F. Cracking the nut of health equity: top down and bottom up pressure for action on the social determinants of health. Promot Educ. 2007; 14(2):90-5. 
21. Hero JO, Zaslavsky AM, Blendon RJ. The United States leads other nations in differences by income in perceptions of health and health care. Health Aff. 2017;36(6):1032-40.

22. Lynch J, Gollust SE. Playing fair: fairness beliefs and health policy preferences in the United States. J Health Polit Policy Law. 2010;35(6):84987.

23. Weil A. Health Affairs. 2020. Available from: https://www.healthaffairs.org/ do/10.1377/hblog20200603.831955/full. Accessed 10 Dec 2020.

24. Carman KG, Chandra A, Weilant S, Miller C, Tait M. 2018 National Survey of Health Attitudes; 2019.

25. Carman KG, Chandra A, Miller C, Trujillo M, Yeung D, Weilant S, et al. Development of the Robert Wood Johnson Foundation National Survey of Health Attitudes: Description and Top-Line Summary Data. Santa Monica: RAND Corporation; 2016. Contract No.: RR-1391-RWJ

26. Pollard MS, Baird MD. The RAND American Life Panel: Technical description. Santa Monica: RAND Corporation; 2017.

27. Carman KG, Eibner C, Paddock SM. Trends in health insurance enrollment, 2013-15. Health Aff. 2015;34(6):1044-8.

28. Robert SA, Booske BC. US opinions on health determinants and social policy as health policy. Am J Public Health. 2011;101(9):1655-63.

29. Chavis DM, Lee KS, Acosta JD. The Sense of Community (SCI) Revised: The Reliability and Validity of the SCl-2. In: 2nd International Community Psychology Conference; Lisbon, Portugal; 2008.

30. Cope MR, Ward C, Jackson JE, Muirbrook KA, Andre AN. Taking another look at the sense of community index: six confirmatory factor analyses. J Commun Psychol. 2020;48(5):1410-23.

31. Feldman S. Structure and consistency in public opinion: the role of core beliefs and values. Am J Polit Sci. 1988;32(2):416-40.

32. Akaike H. Factor-analysis and Aic. Psychometrika. 1987;52(3):317-32.

33. Schwartz G. Estimating the dimension of a model. Ann Stat. 1978;6:461-4.

34. Yang C-C. Evaluating latent class analysis models in qualitative phenotype identification. Comput Stat Data Anal. 2006;50(4):1090-104.

35. Sclove SL. Application of model-selection criteria to some problems in multivariate-analysis. Psychometrika. 1987;52(3):333-43.

36. Muthén B. Should substance use disorders be considered as categorical or dimensional? Addiction. 2006;101(Suppl 1):6-16.

37. Bauer DJ, Curran PJ. The integration of continuous and discrete latent variable models: potential problems and promising opportunities. Psychol Methods. 2004;9(1):3-29.

38. Clark SL, Muthén B, Kaprio J, D'Onofrio BM, Viken R, Rose RJ. Models and strategies for factor mixture analysis: an example concerning the structure underlying psychological disorders. Struct Equ Model Multidiscip J. 2013; 20(4):681-703

39. Muthén LK, Muthén BO. Mplus Software: Version 8. Los Angeles; 2017.

40. StataCorp. Stata Statistical Software: Release 16. College Station: StataCorp LLC; 2019.

41. Cogburn CD. Culture, race, and health: implications for racial inequities and population health. Milbank Q. 2019;97(3):736-61.

42. Kinder DR, Sears DO. Prejudice and politics: symbolic racism versus racia threats to the good life. J Pers Soc Psychol. 1981:40(3):414.

43. Rosenfeld MJ. Moving a mountain: the extraordinary trajectory of same-sex marriage approval in the United States. Socius. 2017;3:2378023117727658.

\section{Publisher's Note}

Springer Nature remains neutral with regard to jurisdictional claims in published maps and institutional affiliations.

Ready to submit your research? Choose BMC and benefit from:

- fast, convenient online submission

- thorough peer review by experienced researchers in your field

- rapid publication on acceptance

- support for research data, including large and complex data types

- gold Open Access which fosters wider collaboration and increased citations

- maximum visibility for your research: over $100 \mathrm{M}$ website views per year

At BMC, research is always in progress.

Learn more biomedcentral.com/submissions 